\title{
FINDING THE WAY TO AMBIDEXTERITY: EXPLORING THE RELATIONSHIPS AMONG ORGANIZATIONAL DESIGN, KNOWLEDGE CREATION AND INNOVATION
}

\section{CITE AS:}

MARTINI A., NEIROTTI P., ALOINI D. (2015), "Finding the Way to Ambidexterity. Exploring the Relationships among Organizational Configurations, Knowledge Creation and Innovation Performance", Int. J. of Innovation Management, Vol. 19, N. 4, DOI: 10.1142/S1363919615500450

\begin{abstract}
Research suggests the firm's structural and contextual attributes that foster ambidexterity, but theory and testing on their combined effects on knowledge creation, ambidexterity, and financial performance remain rather poor. By using a theoretical perspective built on organization design and the knowledge-based view of the firm, this article takes into consideration firms' exploration attainments and exploitation initiatives in relation to both their ability to create knowledge in innovation processes and their capacity to apply it into product innovation. Using data from a survey on 112 hi-tech firms in Italy, results show that organizational context attributes influence firm's degree of ambidexterity in knowledge creation in the innovation processes, but it does not have a direct influence on the actual degree of ambidexterity in innovation development. A fundamental condition to ambidexterity in innovation development is the structural separation of exploration and exploitation innovation initiatives. Specifically, we found that structural separation of these initiatives within the organization directly affects ambidexterity and leads to higher sales growth than when firms achieve ambidexterity through an appropriate organizational context solely. These findings provide a rich explanation of the way firms develop ambidexterity and can obtain superior economic performance from it.
\end{abstract}

Keywords: ambidexterity; innovation; knowledge creation; exploration; exploitation; organizational design.

\section{Acknowledgement}

The authors would like to thank Prof. Emilio Paolucci, Prof. Justin Jansen, Dr. Luca Gastaldi as well as participants at the 2012 DRUID Conference, and reviewers of the 2012 EURAM Conference for their valuable feedback. 


\section{Introduction}

A great deal of management literature considers ambidexterity a key capability for firms' long-term competitive success, positing that firms should be efficient in their management of today's market demands, while simultaneously being adaptive to discontinuities in the environment (Raisch and Birkinshaw, 2008; Simsek, 2009). To be ambidextrous, firms should be able to reconcile conflicting objectives and internal tensions (Magnusson and Martini, 2008; Martini et al., 2012) between exploitation of their established competences and exploration of new opportunities in the innovation process that can be important for their long-term competiveness.

Essentially, research on organizational design recommends two main elements that firms may apply to achieve ambidexterity. First, firms should nurture an organizational context where processes, practices, standards and incentive systems encourage and support human resources to combine both adaptability to discontinuities and alignment to continuous incremental improvements in their tasks environment (Gibson and Birkinshaw, 2004). The second element to achieve ambidexterity lies in the differentiation that firms should apply in the organizational structures, metrics and processes related to explorative innovation endeavours from the ones related to the exploitation of established competencies (Jansen et al., 2006; Jansen et al., 2009).

Despite the large debate about the influence of these solutions in supporting ambidexterity, quantitative studies on this topic still leave some open issues on the way firms should design their organizational configurations to be ambidextrous. Mainly the arguments lay on how these organizational approaches may coexist, and how they can contribute to support ambidexterity in the creation of new knowledge and in its application into new products or production processes (Zahra and George, 2002; Jansen et al., 2005; Chen and Huang, 2009). In this regard, this article deals with two specific research gaps. The first gap refers to the way firms embrace ambidexterity, since so far just few studies take into exam the interplay between building an appropriate organizational context and the structural differentiation of exploration and exploitation endeavours within the firm (Chandrasekaran, Linderman and Schroeder, 2012; Raish, Birkinshaw, Probst and Tushman, 2009; Raish and Birkinshaw, 2008). There is thus little knowledge of whether firms should combine the above levers or whether these solutions may represent two alternative approaches that do not have synergies in supporting ambidexterity. 
The second gap regards the impact that ambidexterity may have on economic performance depending on the way firms achieve ambidexterity. For example, firms that pursue ambidexterity solely through an adaptive and flexible organizational context may become "stuck in the middle" (Porter, 1980) when they try to capitalize exploration endeavours by harmonizing them with more exploitative innovation projects. On the other hand, firms that decide to buffer explorative projects from exploitation of the established technology and market knowledge, may fail in the coordination of the various initiatives (Jansen et al., 2012) or may create redundancies in assets that outweigh the revenue benefits of a superior innovation capability (Venkatraman et al., 2007).

Based on these issues, the article employs a theoretical lens focused on organizational design and the knowledge-based view of the firm (Grant, 1996) and it studies the antecedents and the consequences on economic performance of ambidexterity, over a sample of 112 medium-large hi-tech firms in Italy. To better analyse the contribution that structural differentiation choices and the organisational context have in the process through which firms build ambidexterity, the article looked at two levels of being ambidextrous. The first level is knowledge ambidexterity - the capability of a firm to acquire or develop new knowledge and competencies in both exploration and exploitation endeavours. The second level - defined as innovation ambidexterity - consists in the ability to integrate, apply and exploit new knowledge in radical products (for explorative projects) or in incremental improvements for established products (with regard to exploitation project). In keeping with Attuahene-Gima (2005) and Mei et al. (2013), knowledge ambidexterity refers to a firm's ex-ante strategic objectives in pursuing innovation and it reflects its organizational learning in the domains of exploration and exploitation, whereas innovation ambidexterity refers to an ex-post outcome of the firm's learning processes, namely a firm's actual capacity to deploy their knowledge resources in product innovation. In our view, this approach, by linking the way firms undertake their learning processes with firm performance, offers a more fine-grained understanding of the way firms can get economic returns from ambidexterity. In so doing, the study responds for Raisch and Birkinshaw's call (2008) for more research on the problems related to knowledge use and integration in ambidextrous organizations.

The article is structured as follows. Section 2 describes the theoretical background on the expected role that the organizational context and structural differentiation have in supporting ambidexterity. Section 3 advances four hypotheses over the organizational antecedents and the performance consequences of ambidexterity. Section 4 illustrates the research methodology, while section 5 shows the findings of the analyses. Section 6 discusses the 
contribution of these findings for current literature pointing out some directions for future research.

\section{Theoretical background}

The structural and the contextual views represent the main ways that literature on ambidexterity using a theoretical lens on organizational design follows to investigate how firms can design their organization to successfully manage incremental and discontinuous change (Cantarello et al., 2012). The structural view (Jansen et. al., 2006) refers to the choices that firms should make in designing their organizational structure to facilitate ambidexterity, while the contextual approach (Gibson and Birkinshaw, 2004) focuses on how firms should build a proper organizational setting to encourage employees to engage in ambidextrous learning. Whereas the structural view refers to how firms design their macro structure, the contextual view focuses on how firms build rules, directives and routines that drive behaviours and the micro organization of work in which individuals engage in innovation endeavours.

Following Ghoshal and Bartlett's ideas (1994), there are two groups of attributes that can make an organization's behavioural context appropriate for ambidexterity. The first group refers to what Gibson and Birkinshaw indicate as the 'social context' and reflects a combination of elements that managers build for giving support to employees (e.g. freedom of initiatives at lower levels for experimentation, feedbacks and assistance from middle management and technical areas- towards employees in the operating line ) and for building a climate of trust to induce human resources at each level of the hierarchy in balancing experimentation with alignment to continuous improvement. To make these measures effective for getting innovation done, managers should also adopt a combination of practices, standards and incentives for fostering discipline and stretch in inducing employees to strive for continuous improvement and adaptability, i.e. the ‘performance management context'. Whereas performance management mechanisms induce employees to strive for high-quality results and make them accountable for their success, social support is about providing human resources with the security and latitude they need to perform consistently to their highest potential.

The structural view takes into consideration how firms should design their organizational structures to reconcile exploration and exploitation's contradictory requirements regarding learning routines, metrics and organizational configurations. The choices related to the 
organizational structure can affect the level of a firm's ambidexterity since these decisions influence how firms search for specialization in the use of resources and how coordination occurs outside the formal hierarchy of control (Ouchi, 1979). Specifically, the structural view on ambidexterity takes into exam how the separation of exploration from exploitation in distinct units at the business division or corporate level influence the integration of different knowledge resources that regard the development of a new product or a new production process. Such distinct units can either consist in permanent operational divisions or in fullpledged product development dedicate teams (Wheelwright and Clark, 1992). Whereas units appointed to exploration must be flexible and adaptive, units addressed to exploitation should follow a formal and mechanistic configuration.

For past studies (Bradach, 1997; Tushman and O'Reilly, 1996; Jansen et al., 2006) the design of the organizational context and the way explorative and exploitative innovation endeavours are separated or integrated within the same organizational units represent the main elements of the way firms' organizational configuration affects their ambidexterity capacities. Some research gaps exist on the interplay between the above-mentioned organizational solutions. Specifically, in the words of the knowledge-based view of the firm (Grant, 1996), the organizational context can be interpreted as a key precondition for a "knowledge creating company" (Gibson and Birkinshaw, 2004; Nonaka and Toyama, 2005), whereas structural separation of exploration from exploitation endeavours may permit a more effective integration and capitalization of the knowledge created in the fuzzy front-end of explorative and exploitative projects and may thus be important for bringing both incremental and radical innovations on the market (Tushman and O'Reilly, 1996). There is, however, limited empirical evidence in this regard.

Based on this research gap, this article takes into exam how the firm' organization design decisions about the organizational context and their structures influence their exploration and exploitation attainments in terms of both knowledge creation and transformation/exploitation in actual product and process innovations. Coherently with this focus we do not take an indepth look at how managers' leadership style affects ambidexterity. Although the various dimensions of managerial leadership may affect ambidexterity (i.e. Lubatkin et al. 2006; Jansen et al., 2008), we believe that their omission from the theoretical framework adopted in this study may not produce any critical bias since most of these leadership conditions are reflected in the attributes of the organizational context recommended by Gibson and Birkinshaw (2004) to build ambidexterity. This may hold particularly true in mid-sized enterprises which represents the bulk of our study. Indeed, past research (Romanelli and 
Tushman, 1994) considers top management leadership a crucial driver of discontinuous change in large enterprises given the role that senior managers have in influencing behaviours and attitudes in middle managers, who in large and bureaucratic organizations are "usually" more inclined to support "incremental change" and to hinder the adaptation to discontinuity (Woolridge et al., 2008). By contrast, medium-sized enterprises are usually organized around flat hierarchies, and thus there is a blurred distinction between the middle line and the operating core of the organizational structures.

Given our objective of disentangling the complementarities between the "contextual" and the "structural" ways of building ambidexterity, compared to previous research we study more in the depth the role that organization design has in favouring knowledge creation in innovation processes and the effectiveness of its integration and application. This effectiveness is our outcome measure of ambidexterity and is explored at two levels (figure 1): 1) the generation of innovative knowledge in new products and production processes; 2) the impact that the knowledge created has on the development of new products and production processes (this reflects an act of knowledge integration) and, in turn, the impact that innovation has on the firm's economic performance. In other words, this study adds the consideration that in both exploration and exploitation innovation projects the simultaneous accumulation of knowledge acts as a mediating factor between a firm's actual innovation ambidexterity and its antecedents (see figure 1). In terms of the knowledge-based view of the firm (Grant, 1996; Kogut and Zander, 1992), this approach equates to assess how firms are able to actually deploy their knowledge resource portfolio (Sirmon et al. 2007).

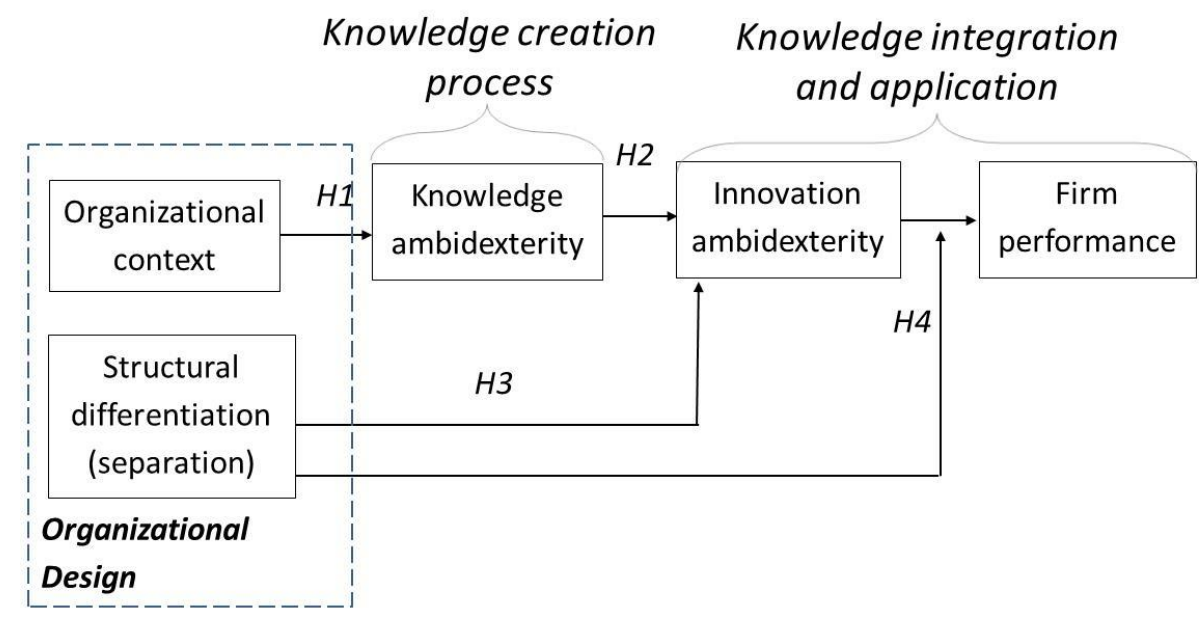

Figure 1. The conceptual model

The focus on the mediating role of knowledge creation in the relationship between innovation antecedents and outcomes is consistent with the great complexity of managing 
knowledge in the innovation process (Chen and Huang, 2009). Indeed once firms acquire new knowledge, they may fail in integrating and applying it effectively (Yli-Renko et al., 2001; Cohen and Levinthal, 1990; Brown and Eisenhardt, 1998). Firms may thus be able to generate new knowledge, but they may fail to embody it into new products because of poor resources synthesis (Zahra and George, 2002; Grant, 1996) or they may fail in appropriating the economic returns from the new products because of ineffective commercialization strategies.

Finally, considering a firm's ambidexterity in building a knowledge portfolio as a key precondition for the actual innovation ambidexterity allows taking better into account the influential links in the relationship between knowledge creation and firm performance. Specifically, in addition to the link between exploitation and incremental innovation, and exploration and radical innovation, there can be other links due to the mutual benefits stemming from these two different learning types (Cao et al. 2009). Accordingly, Mei et al (2013) found that incremental innovation can also stem from explorative learning. In a similar way, Dupouet et al. (2012) show cross-fertilization effects between exploration and exploitation. In other words, new ideas and knowledge useful for exploration often need to be combined with knowledge originally applied to exploitation, and vice versa, knowledge that is initially developed within explorative endeavours can eventually be applied for exploitative purposes related to the improvement of established products. Ambidexterity in terms of both knowledge creation and its outcome on new product development and commercialization can be therefore influenced by the interplay between the organizational context and structural separation of innovation endeavours in different units depending on their degree of discontinuity. The next section advances some hypotheses on the links among these variables.

\section{Hypotheses}

\subsection{The influence of the organizational context}

The contextual ambidexterity view (Gibson and Birkinshaw, 2004) posits that organizational context may lead companies to accumulate new knowledge at a faster pace without the need to necessarily separate exploration and exploitation activities in different research units. Firms can thus resolve the tension between exploration and exploitation within the same organizational unit by creating a consistent set of processes, practices, and incentives. In other words, managers can create the conditions that lead individuals, within the same organizational unit, to maintain a balance between creativity and adaptability in order to 
accommodate strategic or technological changes on one hand, and give attention to detail, efficiency, quality and the use of operational standards on the other. Therefore, exploration of new technological or market domains does not undermine the continuous improvement of quality and efficiency for established products. For example, building on the observation that Toyota has been able to explore and exploit for decades, Brunner et al. (2009) argue that ambidexterity is the ability of employees to engage in problem solving and in the circulation of knowledge throughout the company.

The idea at the core of Gibson and Birkinshaw's (2004) view of the organizational context as an antecedent of ambidexterity is the following: when employees can rely on support and trust from their top/middle managers, and when they follow precise rules, clear standards of performance and behaviour, and a framework of incentives that empowers them and given them accountability, managers may involve them more actively in the simultaneous generation of knowledge in both explorative and exploitation (Sirmon et al., 2007; Hargadon and Sutton, 2000). Following Gibson and Birkinshaw's terminology (2004) henceforth we indicate the first set of conditions as "supportive social relationships" (for embracing both radical and incremental innovation), whereas the second one as "striving performance management systems". Thus:

H1. The more that an organizational context is characterized by an interaction of "striving performance management systems" and "supportive social relationships", the higher the level of ambidexterity in knowledge creation.

\subsection{The mediating role of knowledge creation for innovation ambidexterity}

Although the relationship between the concurrent accumulation of knowledge resources in exploration and exploitation domains and the actual innovation ambidexterity sounds obvious, firms that have built an ambidextrous portfolio of knowledge resources may be unable to deploy it effectively because of inappropriate organizational configurations and rigidity in their combinative capabilities (Van den Bosch et al., 1999). Indeed, there is a general agreement in previous studies: because of poor and ineffective resource synthesis and integration, firms may fail in achieving a full utilization of their knowledge, especially when they have to integrate knowledge from different technological, scientific and market domains (Kogut and Zander, 1992; Zhou and Li, 2012; Hill and Rothaermel, 2003; Zahra and George, 2002; Ahuja and Lampert, 2001). Henderson and Cockburn (1994, p. 65) suggest that a firm's innovation capacity relies on architectural competencies, that is the ability to coordinate an 
extensive flow of information within the firm to use component competencies, that are knowledge and skills on a particular technical or market domains. In addition, a poor use of the available knowledge resources is likely when firms work on too many ideas, as their limited cognitive attention may bring managers to pose insufficient attention to any individual idea (Kogut, 1997; Laursen and Salter, 2006).

Christensen and Bower (2006) offer an example of the difficulties that firms encounter in deploying their portfolio of explorative and exploitative innovation projects by considering the disk drive industry. In this sector, established companies were indeed pioneers in developing discontinuous innovations, but failed to market them, because the new technologies did not address their existing customers' needs. Wrong resource allocation decisions, rigidity of combinative capabilities, and overemphasis on short-term results may indeed lead firms to fail in transforming breakthrough ideas into new products (Van den Bosch et al., 1999).

Goals conflict, time constraints and bounded rationality may thus lead firms to implement some forms of temporary or permanent organizational separation, even when their organizational context already promotes adaptability to accommodate both discontinuities and the alignment needed to improve efficiency and quality for established products (Adler Goldoftas, and Levine, 1999; Lavie et al., 2010). For example, Project Nespresso became successful when Nestlè launched a dedicated unit for it (Raisch, 2008). In a second step the parent company was able to re-use the expertise developed in the Nespresso project for the established mass-market of Nescafe coffee system. The diversities in attitudes, routines, metrics and reporting structures, required to execute exploration and exploitation projects, may therefore lead firms to buffer exploration from exploitation in structured ways by dividing these divergent innovation elements into separate organizational units, embodying distinct strategic and operating logics, cultures and performance metrics.

In terms of knowledge-based view of the firm (Grant, 1996), structural separation of exploration endeavours in specialized units can be viewed as a non-hierarchical team-based organizing configuration that permits a firm to access and integrate knowledge resources that are located in different functional areas of the organization. Separation thus allows to pool together individuals with specialist knowledge that is relevant to exploration endeavours and to allow a more rapid and intense coordination among them compared to let these roles separated in different functional areas. This is particularly effective as knowledge is tacit, is difficult to transfer and cannot be easily modularized (Nonaka and Tayoma, 2005). 
Thanks to structural spatial separation of explorative innovation endeavours from exploitation activities firm may thus become ambidextrous with regard to developing radical and incremental innovation. Past research (Chandrasekaran et al., 2012) has also found that firms maintaining separation of exploration from exploitation only in the form of metrics, processes and $R \& D$ project teams - but not in the form of separate organizational units - are not necessarily ambidextrous, as this type of differentiation only positively affects R\&D exploitative projects performance.

Anecdotal evidence provides many examples of how companies develop ambidexterity from their established business through structural differentiation of radical and explorative projects. This choice is particularly successful when firms combine structural differentiation with an organizational context that exhibits the dimensions suggested by Gibson and Birkinshaw (2004). In a case study on an electrical appliances multinational manufacturer, Dupouet et al. (2012) describe ambidexterity as a process, where ideas and concepts for innovations rise spontaneously in a context favorable to intrapreneurship (Antoncic and Hisrich, 2001). In a second phase, they become actual projects that dedicate explorative unit conduct, only if top managers assess their potential.

In line with this reasoning, structural differentiation may be necessary when firms want to transform new knowledge, accumulated in exploitation and explorative endeavours, in the concurrent achievement of outcomes such as the improvement of efficiency and quality of established products on the one hand, and the entrance in new technological trajectories or market segments, on the other. In accordance with these arguments, Khanagha et al. (2013) found that exploration programs on a new technology paradigm can start through their separation in lightweight project team and then can evolve into experimentation programs that are undertaken by larger heavyweight units made by employees who are "taken away" from their business unit. This program separation can contribute to a closer involvement of customers and suppliers into product development activities and to the use of "trial and error" learning routines. Based on this reasoning, we can expect that the context itself of practices and incentives to foster innovation can be insufficient to achieve a situation of actual ambidexterity, and that this purpose entails some degree of structural differentiation among explorative and exploitative endeavours. This equates to expect that ambidexterity draws upon the combinations of two ways. The first way is an appropriate set of work practices and incentives, which can contribute to the generation of explorative activities besides continuous improvement projects that employees normally undertake. The second way is related to organizational design choices that enable an effective use, integration and capitalization of the 
knowledge created in ambidextrous learning processes. We thus advance the following hypotheses.

H2. Knowledge ambidexterity fully mediates the relationship between firm's innovation ambidexterity and the degree to which the organization context is based on the interaction of "striving performance management systems" and "supportive social relationships".

H3. The degree of structural differentiation of explorative and exploitative innovation initiatives positively affects a firm's actual innovation ambidexterity.

\subsection{Innovation ambidexterity and firm performance}

A fundamental conjecture in ambidexterity literature is that firms' ability to simultaneously explore and exploit can enhance their overall long-term performance. Ambidextrous firms are less susceptible to learning traps that can undermine their competitiveness on the long term (Chandrasekaran et al., 2012; He and Wong, 2004) and their ability to respond to environmental changes. Based on this argument, Auh and Menguc (2005) demonstrate that whereas exploitation produces short-term visible returns, exploration contributes to long-term performance (March, 1991).

Despite a general agreement on the fact that ambidexterity has beneficial consequences on firm performance, the main open issue in the relationship between firm performance and ambidexterity is whether the performance implications of ambidexterity depend on how firms build this capability. In particular, some studies use the arguments of asset redundancies, coordination problems, and conflicts for access to resources among separated units to sustain that ambidexterity produces less benefits on firm performance when it comes from structural separation (Van Looy et al., 2005; Jansen et al., 2012). In other words, firms that separate exploration from exploitation projects may be able to finalize these endeavours, but the introduction of new radical products and incremental improvements in their established products might not be necessarily reflected in revenue growth and superior profits. This is because of loss of economies of scale and poor coordination that stems from separating in different unities resources that are deployed for exploration and exploitation. However, these studies do not report univocal results to support the argument of the negative effects on firm performance due to structural separation.

A corollary of the conceptual framework illustrated in figure 1 is that firms may achieve lower performance improvements when they reach ambidexterity solely through an organizational context fostering adaptability and alignment, than when they adopt also 
structural differentiation. In this regard, Foss et al. (2013) show that firms that use decentralized structures are more able to exploit strategic opportunities related not only to the development of new products, but even to the entry into new market segments. In a similar way, recent studies show that some degree of program separation of explorative endeavours is needed in the phase related to the "go to market" of radical product innovation (Mei et al. 2013). In addition, the reintegration of an explorative separated unit in the institutionalized processes of the organization can harm the organizational capabilities developed within this unit (Durisin and Todorova, 2012). As such, the "capability mutations" following a reintegration of explorative programs in the institutionalized processes of the firm can require a reinvestment in new organizational competence building efforts. Such efforts are expected to have a negative impact on performance, due to a temporary loss of market opportunities (which has a negative impact on revenues) and additional costs due to restoration to the precedent status. This reasoning leads to the following hypothesis.

H4. Innovation ambidexterity leads to higher firm performance when firms adopt structural differentiation of explorative and exploitative projects than when they solely use an organizational context fostering supportive social relationships and striving performance management systems.

\section{Methodology}

\subsection{Sample and data collection}

To test the hypotheses we used survey data collected in a study of medium-sized and large Italian firms in medium and hi-tech industries (selected according to the OECD classification). The sample frame thus includes companies with more than 50 employees and covering all the medium and hi-tech industries. We have randomly extracted five-hundred firms from the AIDA dataset, which is the main financial annual reports information repertoire on Italian firms and it covers the entire population of medium-sized and large enterprises in Italy. Table 1 reports the sample composition by industry type and size. A prevalent part of the sample consists of medium-sized firms (35\% of the firms surveyed have less than 100 employees and only $19 \%$ have more than 1000 employees).

\section{TABLES 1a AND 1b HERE}


Data collection took place through an online survey between May 2009 and February 2010. We contacted companies by phone to introduce the research initiative and identify respondents, who were either R\&D department's vice presidents and directors, or CEOs. Of the 500 surveys mailed in Italy, we received 112 responses (22.4\% response rate).

To test the non-response bias we compared the responses of early and late respondents groups by t-tests, which yielded no statistically significant differences (at 95\% confidence interval). Moreover, we compared responses given by CEOs and the other types of respondents, without finding any systematic response bias due to the respondent role.

\subsection{Measures and construct validation}

For construct operationalization we used multi-item scales that are well consolidated in literature on ambidexterity (Table 2). We used five-point Likert scales with endpoints corresponding to strong disagreement and strong agreement. The scale scores accounts for the mean value of the items. We also assessed a reliability test on all the item groups pertaining to each construct, through Cronbach's alpha test and confirmatory factor analysis (CFA) using Principal Component extraction with Varimax Rotation. Although some refinements were necessary, all the expected constructs were confirmed and we dropped only a few items out (i.e. the items with no loadings reported in the following tables). Cronbach alphas of the constructs resulted in the range between 0.65 and 0.82 and they thus indicated an acceptable degree of reliability.

\section{Dependent variables}

Knowledge ambidexterity. Given that knowledge ambidexterity is a meta-capability in organizational learning processes, we operationalized it through the learning constructs used by Zahra et al. (2000) and Atuahene-Gima (2005). In this context, knowledge ambidexterity reflects: a) a firm's technological and market learning in both familiar and new domains; b) the development of new organizational competencies (Dosi and Teece, 2008) - or the enrichment of pre-existing ones - that are applicable in product development processes. In this perspective, organizational competencies refer to shared pieces of knowledge and routines concerning the governance of coordination and social interactions within the organization and with outside entities (Dosi et al., 2008, p. 1170).

\section{INSERT TABLE 2 HERE}


Innovation ambidexterity. The construct measures the firm actual innovation level implemented in radical and incremental innovation projects. Items are coherent with the measures from He and Wong (2004), Lubatkin et al. (2006) and Cao, Gedajlovic and Zhang (2009).

Knowledge and innovation ambidexterity measures a combined dimension of the exploration and exploitation initiatives, and radical and incremental innovation, respectively. Thus, they are operationalized by multiplying the score of their sub-dimensions. This approach is predominant in quantitative studies on ambidexterity and draws on Gibson and Birkinshaw's (2004) and He and Wong's (2004) operationalizations, which interpret ambidexterity as the ability of simultaneously explore and exploit. However, alternative operationalizations of ambidexterity exist in literature. They consider ambidexterity as a balanced firm focus on exploration and exploitation, irrespective of the magnitude of the firm's achievements in these two domains (see Lubatking et al., 2006; De Visser et al., 2009; Jensen et al., 2009; Revilla and Rodríguez, 2011). Some studies (i.e. Cao et al., 2009) use both the combined view of ambidexterity (based on multiplying exploration and exploitation score) with the balanced view, in an effort to consider more comprehensively both the magnitude and the balance of exploration and exploitation. However, for the sake of model parsimony and due to the small sample size, this study only adopts the combined view of ambidexterity.

We conducted a number of supplementary tests on the knowledge and innovation ambidexterity constructs, in order to test their discriminant validity. Specifically, we performed pairwise comparison of the constructs using a two-factor CFA model at the four sub-constructs level. We estimated each model twice, the first time constraining the correlation coefficient to be equal to one and the second time with no coefficient constrain. The chi-squared difference between the unconstrained model and the constrained one was statistically significant (Chi-square $=25.8, \mathrm{p}$-value $<0.1 \%$ ), thereby confirming that knowledge and innovation ambidexterity are two distinct constructs.

Firm performance. Firm economic performance takes into account the firm's 5 years sales revenue trend compared with the trends observed in the sector. We have extracted data from the AIDA dataset in order to obtain the complete series of firm economic performance between 2005 and 2009. The choice of this time series is consistent with the time horizon given to respondents to express their evaluations of the items composing the constructs under investigation. Indeed, in the questionnaire respondents had to take into account the period 
between 2006 and 2008. In this way, we have also taken into account the ambidexterity lagged effects on firm performance.

While recognizing that firm performance is a multidimensional concept, we only focused on the logarithmic growth rate of sales revenue between 2006 and 2009 for several reasons. Firstly, unlike profitability measures such as ROA, etc., sales revenue growth does not suffer from accounting measurement problems. Secondly, the choice of sales revenue as dependant variable also takes into account that the radical new products may have a lagged impact on profitability due to a lack of learning effects in related operations (which makes the cost of sold goods rise for the new products) and due to R\&D increased expenses (in particular in countries where accounting principles do not allow for their capitalization). Thirdly, ambidexterity returns on sales revenue should be visible as ambidextrous firms are less subject to cannibalization of their old products. By contrast, sales cannibalization may affect firms that focus on incremental innovations consisting in releasing new versions of their established products with a certain periodicity. Finally, sustained sales growth seems to be a reliable proxy indicator of other dimensions of superior firm performance, including longterm profitability and survival (Timmons 1999, Henderson 1999). Moreover, this analysis considers sales growth over five-year time, therefore focusing on medium term performance's trend.

To control for industry effects on performance, we compared the logarithmic growth rate of firms' sales growth rate to the same ratio of aggregate revenues calculated at the industry level (considering industry at the three digit of NACE codes). This adjusted measure of growth revenue presents a further advantage as it also indirectly gives information on economic cycles and other macroeconomic factors such as industry concentration. This advantage is particularly important considering that the economic recession started in 2008 has affected the period where we evaluate ambidexterity impact on performance.

\section{Organization design}

Organizational context. The organizational context use the basis of the construct advanced by Birkinshaw and Gibson (2007) and measures the combined presence of striving performance management systems and supportive social relationships (table 2). Organizational context is thus measured as the mean of these two dimensions.

Structural separation. The construct takes into account the structural differentiation between processes, structures and incentives for exploration and exploitation activities as 
Jansen et al. (2009) suggest. The item considering units separation, depending whether innovation projects inherit long-term or short-term objectives, did not have a high score on the latent factor associated with structural differentiation (table 2). Although speculative, this result may reflect the sample composition and the prevalence of medium-sized firms. These firms are indeed more skeptical and less risk tolerant in engaging very long-term $R \& D$ projects. As such, they may not need a structural separation of projects according to their time orientation. Consequently, our measure of structural differentiation essentially captures a firm's differentiation of continuous incremental innovations from more radical innovations endeavors.

Control variables. We looked for possible confounding effects due to size, the ratio of R\&D spending on annual turnover, firm age, and market turbulence since these factors can influence resource management strategies in innovation processes and their impact on performance. With regard to age, core rigidities and competency traps just moderately affect younger firms and it may be easier for them to act ambidextrously. On the other hand, due to a liability of newness, younger firm may have limited resource endowments, which may hamper them in pursuing both exploration and exploitation and in acquiring the complementary technological and market resources needed to execute ambidextrous strategies.

Size, age and R\&D spending were considered in a logarithmic form. We operationalized turbulence a multi-items 5 level Likert scale (table 2).

\subsection{Analysis methods}

In order to test the research hypotheses we chose hierarchical regression techniques in Stata 11.0. Hierarchical regression adds controls, explanatory variables, and joint effect terms incrementally to gauge relative contributions. For all models, we adopted an additional sensitivity check in order to deal with the limited size of our sample, using bootstrap resampling to generate estimates and robust standard errors. When using a small sample, we can underestimate standard errors, and the regression coefficients can become statistically significant, although they may not be so in the bootstrap methods environment, where the normality assumptions relied upon with large samples are not required. In other words, bootstrapping resampling may provide significantly robust (and thus more prudent) estimates. Concurrently, we adopted the Sobel test in order to confirm mediation of knowledge ambidexterity between the organizational context and the innovation ambidexterity. 


\section{Findings}

Table 3 shows descriptive statistics. Correlation coefficients between knowledge and innovation ambidexterity, as well as between organizational structure and structural separation were high. While the first two constructs are deeply interconnected, the high correlation between organizational structure and structural separation suggests that in many firms these levers coexist, rather than being two alternative ways to achieve ambidexterity.

\section{TABLE 3 HERE}

\subsection{Antecedents of ambidexterity}

The validation of the first three hypotheses was based on ordinary least squares hierarchical regression analyses. All inflation variance factor values were well below the recommended threshold of 5, thus indicating the absence of multicollinearity. Table 4 shows regression results for the antecedents of knowledge and innovation ambidexterity respectively (including the standard errors estimated with a bootstrap approach based on 1000 sample replications).

\section{TABLE 4 HERE}

Models 2 and 5 indicate that the organizational context significantly influences knowledge ambidexterity, but it does not affect innovation ambidexterity. Knowledge ambidexterity, in turn, strongly affects the actual degree of innovation ambidexterity (model 6). These results provide support for hypotheses $\mathrm{H} 1$ and they show that degree of knowledge ambidexterity fully mediates the impact of the organizational context on innovation ambidexterity. Thus, also hypothesis $\mathrm{H} 2$ is supported. A further support to the full mediation of knowledge ambidexterity in the relationship between organizational context and innovation ambidexterity came from a Sobel test $(1992)^{1}$.

Hypothesis $\mathrm{H} 3$ posits that structural differentiation of exploitative and explorative innovation endeavors has a positive and direct effect on the degree of innovation ambidexterity. Model 3 shows that structural differentiation has not impact on the level of knowledge ambidexterity. By contrast, model 5 highlights that structural differentiation has a positive and significant impact on the level of innovation ambidexterity. This effect remains

\footnotetext{
${ }^{1}$ To conserve space the results of the Sobel test are not available in the article but can be requested to the authors.
} 
significant also when model specification includes knowledge ambidexterity as a regressor of innovation ambidexterity (model 6). These results provide support for hypothesis H3.

\subsection{Performance impact of ambidexterity}

Similarly to the above illustrated models on the ambidexterity antecedents, a hierarchical regression analysis approach tested the impact of innovation ambidexterity on firm performance. Model 9 in table 5 indicates that innovation ambidexterity has a positive impact on the logarithmic sales revenue growth rate, thereby providing support to the positive relationship between innovation ambidexterity and performance found by earlier studies.

However, in Hypothesis $\mathrm{H} 4$ we offered a more in-depth description of the relationship between ambidexterity and economic performance, positing that when firm achieve ambidexterity through the structural separation of exploration endeavors from exploitation innovation initiatives, the performance impact is greater. To test this hypothesis, the regression specification considered the interaction effect of innovation ambidexterity with structural separation, and the interaction of innovation ambidexterity with organizational context. In order to test these interaction effects, the models considered these variables by using their scores normalized to a mean of zero and a standard deviation of one.

Model 10 (table 5) shows that the interaction between ambidexterity and structural differentiation is positive and significant, whereas the interaction between ambidexterity and the organizational context is non-significant. Ambidexterity's impact on performance therefore grows in presence of structural differentiation. Figure 2 depicts the interaction.

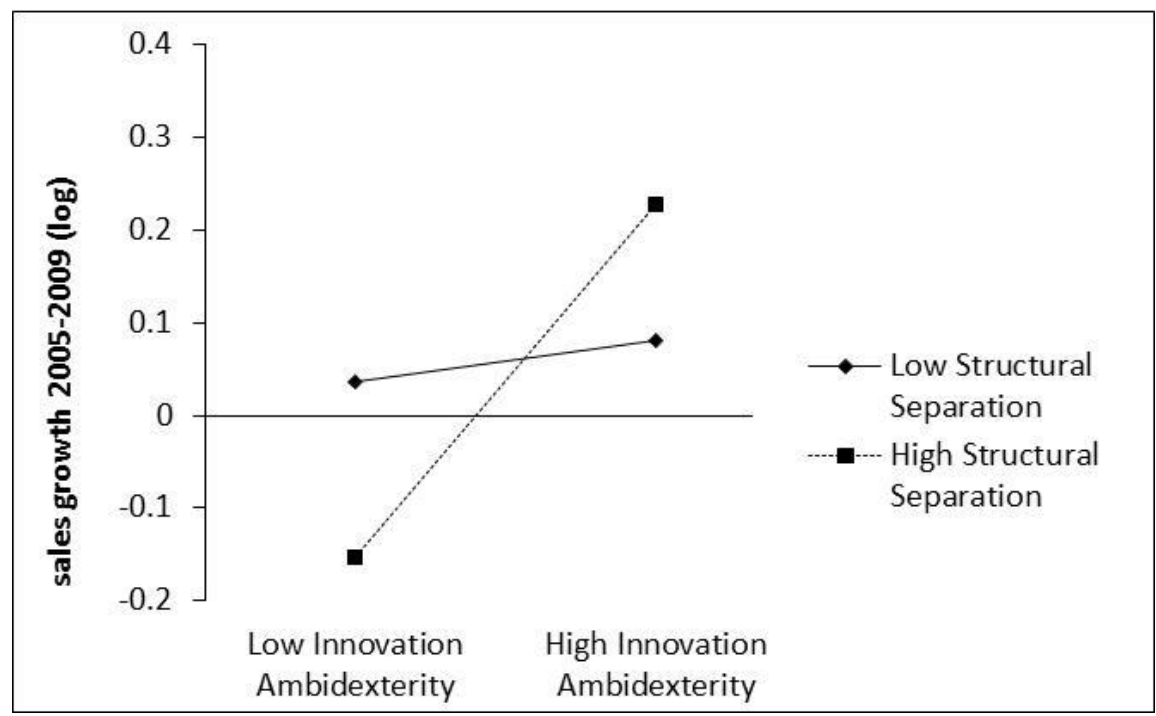

Figure 2. Performance effects due to structural ambidexterity. Interaction effect estimates from linear regression model (model 6) 
A supplementary analysis served to validate this finding and used values of organizational context, structural separation, and innovation ambidexterity that were dichotomized using the median values as cut-off points. This variable transformation served to identify four distinct company groups. The first group includes firms without a considerable degree of innovation ambidexterity (no ambidexterity). The second group includes firms with a high ambidexterity level despite the low level of structural separation and the lack of an organizational context $\grave{a}$ la Birkinshaw and Gibson (2004). It is worthwhile noticing that these firms are a minority in the sample (they are 11 on a total sample of 112 firms). The third group captures firms that follow a "pure contextual" ambidexterity approach as they achieved a high ambidexterity level with an adequate organizational context and a low degree of structural separation of exploration initiatives from exploitative innovation. The fourth group includes firms that achieved ambidexterity through structural separation of exploration from exploitation.

\section{INSER TABLE 5 AND 6 ABOUT HERE}

We compared sales growth rates across these four groups through an Anova analysis and a Kruskall-Wallis non-parametric test. Table 6 reports the result of this analysis and indicates firms in the third and the fourth group as organizations pursuing "pure contextual ambidexterity", and "ambidexterity in presence of structural separation", respectively. Non parametric and Anova tests indicate that when firms achieve ambidexterity without structural separation and by relying only on the development of an organizational context à la Gibson and Birkinshaw (2004), they report lower (and negative) growth rates in sales revenue than companies that introduce, at a certain time, some degree of organizational separation in the exploration innovation processes. Table 7 presents a robustness check based on comparing the logarithmic growth rate of sales revenue (through a paired Student's t-test executed with a bootstrap resampling approach, based on 1000 sample replications) between firms that achieved ambidexterity through structural separation and the other three groups of companies. This approach confirms that when firms achieve ambidexterity through structural separation, this capability leads firms to a higher sales growth that when they pursue it only through an appropriate organizational context. This analysis confirms the results of model 10 in table 5 and thus supports hypothesis $\mathrm{H} 4$.

INSERT TABLE 7 HERE 


\section{Discussion and conclusions}

\subsection{Key Findings}

The theoretical insights and the empirical findings discussed in this paper contribute to illustrate the way firms can achieve ambidexterity and the impact that ambidexterity has on firm performance, depending on the way firms have built this capability. In so doing, the paper highlights three key results. These results contribute to responds to the call for studies showing a fine-grained process view centered on how firms create and integrate knowledge resources in their innovation endeavours (Raisch and Birkinshaw, 2008).

Firstly, the article illustrates how firms that have built an organizational context made of the preconditions illustrated by Gibson and Birkinshaw (2004) achieve ambidexterity. Specifically, firms where the organizational context is characterized by an interaction of performance management systems and social relationships that induce employees striving for experimentation and alignment to continuous improvement (i.e. discipline, stretch, support and trust in the words of the two authors) are more able to combine exploitation and exploration in their dynamics of knowledge creation than firms without these preconditions. The combination of exploitation and exploration in knowledge creation in turn positively affects the actual achievement of innovation ambidexterity. In other words, the learning capabilities founded on an appropriate organizational context appear as a necessary condition for knowledge creation, but they are not sufficient condition for achieving an actual degree of innovation ambidexterity, since this capacity depends on how firms are able to integrate knowledge resources in their innovation processes.

The second important result is that the structural separation of exploration from exploitation endeavours in different units is not necessarily a key precondition for the creation of a more ambidextrous portfolio of knowledge resources but it is rather critical for the actual achievement of ambidexterity in product innovation. Thus, hierarchical regression models highlight that an organizational context á la Gibson and Birskinshaw (2004) and structural separation play a critical role in two distinct moments of innovation processes, in the stage of knowledge creation and in the subsequent phase of knowledge incorporation in new products, respectively. In other words, organizations with an appropriate blend of trust, support, discipline and stretch may result the right context for knowledge generation in both exploration and exploitation initiatives (Gibson and Birkinshaw, 2004). However, if companies want to capitalize on their knowledge resources for the simultaneous development of new radical products and improvement of the established ones, they must introduce and 
keep some structural separation eventually in their innovation process. This finding suggests that firms may build ambidexterity by combining contextual conditions with the structural differentiation in a dual structure of exploration and exploitation endeavours. The positive correlation between these two constructs further confirms this evidence and supports the idea that some complementarities exist between the different organizational solutions for ambidexterity (Raish and Birkinshaw, 2008).

The third key finding concerns the impact of ambidexterity on firm performance. Specifically, the research indicates that firms achieving innovation ambidexterity had higher growth rates in sales between 2005 and 2009. This benefit was more evident when firms achieved ambidexterity in presence of choices of separating exploration and exploitation in different units. This result reinforces earlier studies which found that radical innovations may open-up new markets and strategic opportunities (Christensen and Bower, 2006) which require the development of new marketing competencies and some specialization and task division (Foss et al. 2013; Durisin and Todorova, 2012). As such, this result clarifies that redesign of organizational structures is not simply one of the possible alternatives to achieve ambidexterity but it is crucial for applying knowledge produced in exploration and exploitation activities into improved operations and product innovation and, consequently, for getting superior economic performance. This represents the main novelty aspect brought by our study in the debate about the ways firm may use to build ambidexterity. Despite the fact that the time window under analysis in this research does not give the possibility to fully assess the long-term performance impact of ambidexterity, the evidence on the positive impact of ambidexterity on revenue growth is in line with He and Wong's (2004) study. However, the positive impact of structural ambidexterity on performance is discordant with some previous studies that did not find either a positive impact of structural differentiation on ambidexterity, or its benefits on performance (Chandrasekaran et al., 2012; Jansen et al., 2012). This discordance might be the consequence of differences in structural differentiation operationalization or in sample characteristics across studies. Whereas other studies only consider structural differentiation in terms of non-spatial mechanisms that allow resources sharing between exploration and exploitation projects, this work considers structural differentiation as the creation of dual organizational structures that independently pursue exploitation and exploration. Moreover, the fact that in this research medium-sized enterprises prevail in the sample, could explain why separation was not detrimental to the success of innovation endeavours as the smaller the firm size, the easier the coordination and sharing of resources across units 
On the whole, these three key findings - by illustrating the complementarities that the organizational context and structural separation respectively have in knowledge creation and in knowledge integration - show the relevance that the knowledge-based view of the firm (Grant, 1996) can have for explaining how firms develop ambidexterity in their innovation processes.

From a managerial perspective, the main implication from this result is that organizational contexts that support employees in participating simultaneously in exploration and exploitation initiatives may succeed in creating applicable knowledge in these dual domains. However, the knowledge created in contextual ambidexterity processes is just an intermediate output therefore capitalizing these outputs by achieving simultaneous success in exploration and exploitation may require firms to separate these initiatives into different units. Both useful knowledge for radical products and incremental innovation initiatives may originate within the same organizational unit. However going ahead in the innovation process, firms may need to develop technological and market competencies requiring isolation of radical innovation initiatives into ad-hoc structures. Concerning this conclusion, an important issue for managers - and even for scholars approaching future research - is to understand at which point of the innovation processes some forms of heavyweight separation become necessary. Therefore, future studies should undertake the following questions: can spatial separation be important immediately at the start of explorative innovation endeavours when new innovative ideas and knowledge emerge? Or may this organizational choice become necessary only in the subsequent phases, when firms must integrate new knowledge resources with other technological or market knowledge and when they have to finalize radical innovation projects must be finalized (Depouet et al., 2012)?

\subsection{Limitation and future developments}

In raising the above evidence, the paper presents some limitations that also represent directions for future research. Firstly, the five point Likert scale used to measure the innovation performance and knowledge constructs - although well consolidated in the literature - may have only captured limited attributes of the exploration versus exploitation distinction. Particularly, our scale fails to capture whether firms pursue ambidexterity in a simultaneous way (Tushman and O'Reilly, 1996) or by a time-paced sequence of exploration and exploitation (Brown ad Eisenhardt, 1997; Simsek and Hulland, 2009). 
In addition, environmental conditions such as industry dynamism and competitiveness, or structural conditions such as firm size or age could moderate the relationship between ambidexterity and performance. The limited sample size did not allow testing the possible presence of these moderation effects. Accordingly, future research may dedicate to generalise our results to different industry and firm size conditions. It can be plausible that the lower the firm size the lower the need to separate in different units explorative from exploitative innovation projects. Finally, the extent to which results from these studies are generalizable represents another limitation. This study mainly selected medium-sized firms in medium and high-tech sectors in Italy. However, innovation can strongly differ in large vs. small firms and cultural-contextual and environmental variables might influence it. Future research should thus include cross-country studies, as well as a comparison of ambidexterity`s antecedents and consequences in different sectors and competitive environments.

\section{References}

Adler, P. S., Goldoftas, B. and Levine, D.I. (1999), "Flexibility versus efficiency? A case study of model changeovers in the Toyota production system", Organization Science, Vol. 10, pp. 43-68.

Ahuja, G. and Lampert, C.M. (2001), "Entrepreneurship in the large corporation: a longitudinal study of how established firms create breakthrough inventions", Strategic Management Journal, Vol. 22, pp. 521-543.

Andriopolus, C. and Lewis, M.W. (2009), "Exploitation-exploration tensions and organizational ambidexterity: managing paradoxes of innovation”, Organization Science, Vol. 20, pp. 696-717.

Antoncic, B. and Hisrich, R.D. (2001), "Intrapreneurship: construct refinement and cross-cultural validation". Journal of Business Venturing, Vol. 16, pp. 495-527.

Atuahene-Gima, K. (2005), "Resolving the capability-rigidity paradox in new product innovation", Journal of Marketing, Vol. 69, pp. 61-83.

Auh, S. and Menguc, B. (2005), "Balancing exploration and exploitation: the moderating role of competitive intensity”, Journal of Business Research, Vol. 58, pp. 1652-1661.

Birkinshaw, J. and Raish, S. (2008), "Organizational ambidexterity: antecedents, outcomes, and moderators", Journal of Management, Vol. 34, pp. 375-409.

Bradach, J.L. (1997), "Using the Plural Form in the Management of Restaurant Chains", Administrative Science Quarterly, Vol. 42, pp. 276-303.

Brown, S. and Eisenhardt, K. (1998), "Competing on the edge: strategy as structured chaos". Boston, MA: Harvard Business School.

Brunner, D. J., Staats, B. R., Tushman, M. L. and Upton, D.M. (2009), "Wellsprings of creation: perturbation and the paradox of the highly disciplined organization". Unpublished result. (Working Paper No. 09-011). Cambridge, MA: Harvard Business School.

Cantarello, S., Martini, A. and Nosella, A. (2012), "A multi-level model for organizational ambidexterity in the search phase of the innovation process", Creativity and Innovation Management, Vol. 21, pp. 28-48. 
Cao, Q., Gedajlovic, E. and Zhang, H.P. (2009), "Unpacking organizational ambidexterity: dimensions, contingencies, and synergistic effects”, Organization Science, Vol. 20, pp. 781-796.

Cao, Q., Simsek, Z. and Zhang, H.P. (2009), "Modelling the joint impact of the CEO and the TMT on organizational ambidexterity”, Journal of Management Studies, Vol. 46, pp. 597-624.

Chandrasekaran, A., Linderman, K. and Schroeder, R. (2012), “Antecedents to ambidexterity competency in high technology organization", Journal of Operations Management, Vol. 30, pp. 134-151.

Chang, Y-Y., and Hughes M. (2011), Drivers of innovation ambidexterity in small-to-medium-sized firms, European Management Journal, in press.

Chen, C. J. and Huang, J.W. (2009), "Strategic human resource practices and innovation performance - the mediating role of knowledge management capacity", Journal of Business Research, Vol. 62, pp. 104-114.

Christensen, C. M. and Bower, J.L. (1996), "Customer power, strategic investment, and the failure of leading firms”, Strategic Management Journal, Vol. 17, pp. 197-218.

Cohen, W.M. and Levinthal, D.A. (1990), "Absorptive capacity: a new perspective on learning and innovation", Administrative Science Quarterly, Vol. 35, pp. 128-152.

De Visser, M., de Weerd-Nederhof, P., Faems, D., Song, M., van Looy, B. and Visscher, K. (2010), "Structural ambidexterity in NPD processes: a firm-level assessment of the impact of differentiated structures on innovation performance", Technovation, Vol. 30, pp. 291-299.

Dosi, G. and Teece, D.J. (1998), “Organizational competences and the boundaries of the firms' in markets and organizations. In: R. Arena, and C. Longhi (Eds.), Springer-Verlag. Berlin/Heidelberg, New York.

Dosi, G., Faillo, M. and Marengo, L. (2008), “Organizational capabilities, patterns of knowledge accumulation and governance structures in business firms: an introduction”, Organization Studies, Vol. 29, pp. 1165 1185.

Duncan, R.B. (1976), “The ambidextrous organization: designing dual structures for innovation”. In: Kilmann, R. H., Pondy, L. R., and Slevin, D. (Eds.), The Management of Organization (pp. 167-88). New York: North-Holland, 1.

Durisin, B. Todorova G. (2012), “A study of the performativity of the "Ambidextrous Organizations" Theory: Neither Lost in nor Lost Before Translation”, Journal of Product Innovation Management, Vol. 29, pp. 5375.

Dupouet, O., Bouzdine-Chameeva, T. and Lakshman, C. (2012), “Organizing ambidexterity across multiple levels of analysis: sensing and seizing opportunities for sustained performance". Unpublished. Proceeding of EURAM 2012 Conference.

Ebben, J. and Johnson, A. (2005), "Efficiency, flexibility, or both? Evidence linking strategy to performance in small firms", Strategic Management Journal, Vol. 26, pp. 1249-1259.

Eisenhardt, K.M. (2000), "Paradox, spirals, ambivalence: the new language of change and pluralism", Academy of Management Review, Vol. 25, pp. 703-705.

Fang, C., Lee, J. and Shilling, M. (2009), "Balancing exploration and exploitation through structural design: the isolation of subgroups and organizational learning", Organization Science, Vol. 21, pp. 625-642.

Foss, N.J., Lyngsie J. and Zahra, S. (2013), "The role of external knowledge sources and organizational decisn in the process of opportunity exploitation”, Strategic Management Journal, forthcoming 
Gibson, C. B. and Birkinshaw, J. (2004), "The antecedents, consequences, and mediating role of organizational ambidexterity", Academy of Management Journal, Vol. 47, pp. 209-226.

Gibson, C. B. and Birkinshaw, J. (2007), “The ambidextrous organization”, AIM Research.

Goodman, L.A. (1960), "On the exact variance of products", Journal of the American Statistical Association, Vol. 55, pp. 708-713.

Goshal, S. and Bartlett, C.A. (1994), "Linking organizational context and managerial action: the dimensions of quality of management", Strategic Management Journal, Vol. 15, pp. 91-112.

Grant, R.M. (1996), “Toward a knowledge-based theory of the firm”, Strategic Management Journal, Vol. 17, pp. 109-122.

Hardagon, A. and Sutton, R.I. (2000), "Building and innovation factory”, Harvard Business Review, Vol. 78, pp. $157-166$

He, Z.-L. and Wong, P. K. (2004), "Exploration vs. exploitation: an empirical test of the ambidexterity hypothesis", Organization Science, Vol. 15, pp. 481-94.

Henderson, R. and Cockburn, I. (1994), "Measuring competence? Exploring firm effects in pharmaceutical research”, Strategic Management Journal, Vol. 15, pp. 63-84.

Hill, C.W.L. and Rothaermel, F.T. (2003), "The performance of incumbent firms in the face of radical technological innovation", Academy of Management Review, Vol. 28, pp. 257-274.

Iansiti, M, and Clark, K.B. (1994), "Integration and dynamic capability: evidence from product development in automobiles and mainframe computers", Industrial and Corporate Change, Vol. 3, pp. 557-605.

Jansen, J.J.P., Van den Bosch, F.A. and Volberda H.W. (2005), "Exploratory innovation, exploitative innovation, and ambidexterity: the impact of environmental and organizational antecedents", Schmalenbach Business Review, Vol. 57, pp. 351-363.

Jansen, J., Simsek, Z. and Cao, Q. (2012), “Ambidexterity and performance in multiunit contexts: cross-level moderating effects of structural and resource attributes", Strategic Management Journal, online Early View.

Jansen, J., Van den Bosch, F.A.J. and Volberda, H.W. (2006), "Exploratory innovation, exploitive innovation and performance: effects of organizational antecedents and environmental moderators", Management Science, Vol. 52, pp. 1661-1674.

Jansen, J., George, G., Van den Bosch, F.A.J., Volberda, H.W. (2008) Senior Team Attributes and Organizational Ambidexterity: The Moderating Role of Transformational Leadership, Journal of Management Studies, Vol. 45, pp. 983-1007.

Jansen, J.J.P., Tempelaar, M.P., Van den Bosch, F.A.J. and Volberda, H.W. (2009), "Structural differentiation and ambidexterity: the mediating role of integration mechanisms”, Organization Science, Vol. 20, pp. $797-$ 811.

Jayanthi, S. and Sinha, K.K. (1998), “Innovation implementation: a chaos theoretic empirical analysis”. Journal of Operations Management, Vol. 16, pp. 471-495.

Khanagha S., Volberda H., Sidhu J., Oshri I. (2013), "Management Innovation and Adoption of Emerging Technologies: The Case of Cloud Computing”, European Management Review, Vol. 10, pp. 51-67.

Kogut, B. and Zander, U. (1992), "Knowledge of the firm, combinative capabilities, and the replication of technology, Organization Science, Vol. 3, pp. 383-397. 
Kristal, M. M., Huang, X. and Roth, A.V. (2010), "The effect of an ambidextrous supply chain strategy on combinative competitive capabilities and business performance", Journal of Operations Management, Vol. 28 , pp. $415-429$.

Laursen, K. and Salter, A. (2006), "Open for innovation: the role of openness in explaining innovation performance among U.K. manufacturing firms”, Strategic Management Journal, Vol. 27, pp. 131-150.

Lavie, D. and Rosenkopf, L. (2006), “Balancing exploration and exploitation in alliance formation”, Academy of Management Journal, Vol. 49, pp. 797-818.

Lavie, D., Kang, J. and Rosenkopf, L. (2011), "Balance within and across domains: the performance implications of exploration and exploitation in alliances”, Organization Science, Vol. 22, pp. 1517-1538.

Lavie, D., Stettner, U. and Tushman, M. (2010), "Exploration and exploitation within and across organizations", Academy of Management Annals, Vol. 4, pp. 109-155.

Li, C-R., Lin, C-J. and Chu, C-P. (2008), "The nature of market orientation and the ambidexterity of innovation", Management Decision, Vol. 46, pp. 1002-1026.

Li, Y-H. and Huang, J.W. (2012), “Ambidexterity's mediating impact on product development proficiency and new product performance”, Industrial Marketing Management, in press.

Lubatkin, M. H., Simsek, Z., Ling, Y. and Veiga J.F. (2006), “Ambidexterity and performance in small- to medium-sized firms: the pivotal role of TMT behavioral integration”, Journal of Management, Vol. 32, pp. 1-17.Magnusson, M. and Martini, A. (2008), "Dual organisational capabilities: from theory to practice- the next challenge for continuous innovation”, International Journal of Technology Management, Vol. 42, pp. 1-19.

March, J.G. (1991), "Exploration and exploitation in organizational learning”, Organization Science, Vol. 2, pp. 71-87.

Martini, A., Timenes Laugen, B., Gastaldi, L. and Corso, M. (2013), “Continuous innovation: towards a paradoxical, ambidextrous combination of exploration and exploitation", International Journal of Technology Management, Vol. 62, pp. 1-15.

Mei M.Q, Laursen, K. and Atuahene-Gima K. (2013), “Learning to Innovate: How Does Ambidextrous Learning Matter to Radical and Incremental Innovation Capabilities?”, 35th DRUID Celebration Conference 2013, Barcelona, Spain, June 17-19.

Menguc, B. and Auh, S. (2010), "Development and return on execution of product innovation capabilities: the role of organizational structure”, Industrial Marketing Management, Vol. 39, pp. 820-831.

Mom, T.J.M., Van den Bosch, F.A.J. and Volberda, H.W. (2009), "Understanding variation in managers' ambidexterity: investigating direct and interaction effects of formal structural and personal coordination mechanisms", Organization Science, Vol. 20, pp. 812-828.

Morgan, R. E. and Berthon, P. (2008), "Market orientation, generative learning, innovation strategy and business performance inter-relationships in bioscience firms", Journal of Management Studies, Vol. 45, pp. 13291353.

Nonaka, I. and Toyama, R. (2005) The theory of the knowledge-creating firm: subjectivity, objectivity and synthesis, Industrial and Corporate Change, Vol. 14, pp. 419-436.

Ouchi, W.G. (1979) A conceptual framework for the design of organizational control mechanisms, Management Science, 25, 833-848. 
Popadiuk, S. (2011), “Scale for classifying organizations as explorers, exploiters or ambidextrous”, International Journal of Information Management, in press.

Porter M. E. (1980), Competitive strategy techniques for analyzing industries and competitors. New York: free press.

Raisch, S. (2008), "Balanced structures: designing organizations for profitable growth", Long Range Planning, Vol. 41, pp. 483-508.

Raisch, S. and Birkinshaw, J. (2008), “Organizational ambidexterity: antecedents, outcomes, and moderators”, Journal of Management, Vol. 34, pp. 375-409.

Raisch, S., Birkinshaw, J., Probst, G. and Tushman, M.L. (2009), "Organizational ambidexterity: balancing exploitation and exploration for sustained performance", Organization Science, Vol. 20, pp. 685-695.

Revilla, E., and Rodríguez, B. (2011), “Team vision in product development: how knowledge strategy matters”, Technovation, Vol. 31, pp. 118-127.

Romanelli, E., Tushman, M.L. (1994), “Organizational Transformation as Punctuated Equilibrium: An Empirical Test", Academy of Management Journal, Vol. 37, pp. 1141-1166.

Sarkees, M. and Hulland, J. (2009), "Innovation and efficiency: it is possible to have it all", Business Horizons, Vol. 52, pp. 45-55.

Simsek, Z. (2009), “Organizational ambidexterity: towards a multilevel understanding”, Journal of Management Studies, Vol. 46, pp. 597-624.

Simsek, Z., Heavey, C. and Veiga, J.F. (2009), “A typology for aligning organizational ambidexterity's conceptualizations, antecedents, and outcomes”, Journal of Management Studies, Vol. 46, pp. 864-878.

Sirmon, D.G., Hitt, M.A. and Ireland R.D. (2007), "Managing firm resources in dynamic environments to create value: Looking inside the black box", Academy of Management Review, Vol. 32, pp. 273-292.

Smith, K., Gupta, A.K.G. and Shalley, C.E. (2006), "The interplay between exploration and exploitation", Academy of Management Journal, Vol. 49, pp. 693-706.

Smith, W. K., and Tushman, M. L. (2005), "Managing Strategic Contradictions: A Top Management Model for Managing Innovation Streams”, Organization Science, Vol. 16 N. 5, pp. 522-536.

Sobel, M.E. (1982), “Asymptotic confidence intervals for indirect effects in structural equation models”. In: S. Leinhardt (Eds.), Sociological methodology (pp. 290-312). Washington, DC: American Sociological Association.

Subramaniam, M. and Youndt, M.A. (2005), "The influence of intellectual capital on the nature of innovative capabilities", Academy of Management Journal, Vol. 48, pp. 450-464.

Timmons, J. (1999), New Venture Creation: Entrepreneurship for the 21st Century, 5th ed. Irwin/McGraw-Hill, Boston, MA.

Tushman, M.L. and O’Reilly, C. (1996), “Ambidextrous organizations: Managing evolutionary and Revolutionary Change”, California Management Review, Vol. 38, pp. 8-30.

Van den Bosch, F.A.J., Volberda, H.W. and de Boer, M. (1999), "Coevolution of firm absorptive capacity and knowledge environment: organizational forms and combinative capabilities”, Organization Science, Vol. 10, pp. 551-68.

Van Looy, B., Martens, T., and Debackere K. (2005), "Organizing for continuous innovation: on the sustainability of ambidextrous organizing”, Creativity and Innovation Management, Vol. 14, pp. 208-22. 
Venkatraman, N., Lee, C. H., and Iyer, B. (2007), "Strategic ambidexterity and sales growth: a longitudinal test in the software sector". Unpublished manuscript (earlier version presented at the Academy of Management Meeting, 2005).

Wang, C. L., and Rafiq, M. (2012), “Ambidextrous organizational culture, contextual ambidexterity and new product innovation: a comparative study of UK and Chinese high-tech firms", British Journal of Management, in press.

Bill Wooldridge, B., Schmid, T., Floyd. S.W (2008) “The Middle Management Perspective on Strategy Process: Contributions, Synthesis, and Future Research”, Journal of Management, Vol. 34, pp. 1190-1221

Wheelwright, S.C., and Clark, K.B. (1992), Revolutionizing product development: quantum leaps in speed, efficiency, and quality. New York, NY: free press.

Yli-Renko, H., Autio, E., and Sapienza, H.J. (2001), "Social capital, knowledge acquisition, and knowledge exploitation in young technology-based firms”, Strategic Management Journal, Vol. 22, pp. 587-613.

Zahra, S.A., and George, G. (2002), "Absorptive capacity: a review, reconceptualization, and extension", Academy of Management Review, Vol. 27 N. 2, pp. 185-203.

Zahra, S.A., Ireland, R.D., and Hitt, M.A. (2000), "International expansion by new venture firms: International diversity, mode of market entry, technological learning, and firm performance”, Academy of Management Journal, Vol. 43, pp. 925-950.

Zhou, K.Z. and Li, C.B. (2012), "How knowledge affects radical innovation: knowledge base, market knowledge acquisition, and internal knowledge sharing”, Strategic Management Journal, Vol. 33, pp. 1090-1102. 